\title{
Pre-treatment MRI minimum apparent diffusion coefficient value is a potential prognostic imaging biomarker in cervical cancer patients treated with definitive chemoradiation
}

\author{
Daniel Grossi Marconi ${ }^{1 *}$, Jose Humberto Tavares Guerreiro Fregnani ${ }^{2}$, Rodrigo Ribeiro Rossini ${ }^{3}$,
}

Ana Karina Borges Junqueira Netto ${ }^{3}$, Fabiano Rubião Lucchesi ${ }^{3}$, Audrey Tieko Tsunoda ${ }^{2}$ and Mitchell Kamrava ${ }^{4}$

\begin{abstract}
Background: Diffusion Weighted (DW) Magnetic Resonance Imaging (MRI) has been studed in several cancers including cervical cancer. This study was designed to investigate the association of DW-MRI parameters with baseline clinical features and clinical outcomes (local regional control (LRC), disease free survival (DFS) and disease specific survival (DSS)) in cervical cancer patients treated with definitive chemoradiation.

Methods : This was a retrospective study approved by an institutional review board that included 66 women with cervical cancer treated with definitive chemoradiation who underwent pre-treatment MRI at our institution between 2012 and 2013. A region of interest (ROI) was manually drawn by one of three radiologists with experience in pelvic imaging on a single axial $\mathrm{CT}$ slice encompassing the widest diameter of the cervical tumor while excluding areas of necrosis. The following apparent diffusion coefficient (ADC) values $\left(\times 10^{-3} \mathrm{~mm}^{2} / \mathrm{s}\right)$ were extracted for each ROI: Minimum - $A D C_{\text {min, }}$ Maximum - $A D C_{\text {max }}$ Mean - $A D C_{\text {mean, }}$ and Standard Deviation of the $A D C-A D C_{\text {dev }}$. Receiver operating characteristic $(R O C)$ curves were built to choose the most accurate cut off value for each ADC value. Correlation between imaging metrics and baseline clinical features were evaluated using the Mann Whitney test. Confirmatory multi-variate Cox modeling was used to test associations with LRC (adjusted by gross tumor volume - GTV), DFS and DSS (both adjusted by FIGO stage). Kaplan Meyer curves were built for DFS and DSS. A $p$-value $<0.05$ was considered significant.

Women median age was 52 years (range 23-90). $67 \%$ had FIGO stage I-II disease while $33 \%$ had FIGO stage III-IV disease. Eighty-two percent had squamous cell cancer. Eighty-eight percent received concurrent cisplatin chemotherapy with radiation. Median EQD2 of external beam and brachytherapy was 82.2 Gy (range 74-84).

Results: Women with disease staged III-IV (FIGO) had significantly higher mean ADC max values compared with those with stage I-II (1.806 (0.4) vs $1.485(0.4), p=0.01)$. Patients with imaging defined positive nodes also had significantly higher mean ( $\pm \mathrm{SD}) A \mathrm{ADC}_{\max }$ values compared with lymph node negative patients (1.995 (0.3) vs $\left.1.551(0.5), p=0.03\right)$. With a median follow-up of 32 months (range 5-43) 11 patients (17\%) have developed recurrent disease and 8 (12\%) have died because of cervical cancer. ROC curves based on DSS showed optimal cutoffs for ADC min $\left(0.488 \times 10^{-3}\right)$, $A D C_{\text {mean }}\left(0.827 \times 10^{-3}\right), A D C_{\max }\left(1.838 \times 10^{-3}\right)$ and $A D C_{\text {dev }}\left(0.148 \times 10^{-3}\right) . A D C_{\text {min }}$ higher than the cutoff was (Continued on next page)
\end{abstract}

\footnotetext{
* Correspondence: dgmarconi@gmail.com

${ }^{1}$ Department of Radiation Oncology, Barretos Cancer Hospital, Antenor

Duarte Villela, 1331, Barretos, Sao Paulo 14784-400, Brazil

Full list of author information is available at the end of the article
} 


\begin{abstract}
(Continued from previous page)
significantly associated with worse DFS (HR $=3.632-95 \% \mathrm{Cl}: 1.094-12.054 ; p=0.035)$ and DSS $(\mathrm{HR}=4.401-95 \% \mathrm{Cl}: 1$. 048-18.483; $p=0.043)$.

Conclusion: Pre-treatment $A D C_{\text {max }}$ measured in the primary tumor may be associated with FIGO stage and lymph node status. Pre-treatment $A D C_{\text {min }}$ may be a prognostic factor associated with disease-free survival and disease-specific survival in cervical cancer patients treated with definitive chemoradiation. Prospective validation of these findings is currently ongoing.
\end{abstract}

Keywords: Cervical cancer, Diffusion weighted imaging, Chemoradiation, MRI

\section{Background}

In Brazil, it is estimated that 18,500 women are diagnosed with cervical cancer annually, and 8,400 die [1]. While screening rates for cervical cancer have improved in many countries, there are still a significant number of women who present with locally advanced disease that will require definitive treatment with chemoradiation. Advances in image-guided brachytherapy using Magnetic Resonance Imaging/planning (MRI) rather than 2-dimmensional techniques is significantly improving the outcomes, and changing their patterns of recurrence [2]. With imagebased brachytherapy the vast majority of these patients are achieving local control of their tumors with limited serious acute or late morbidity. More women are now recurring with distant rather than local failures with marginal outcomes with systemic therapy in these cases [3]. Efforts are now underway on the OUTBACK trial [4], for example, to potentially improve these clinical outcomes with the addition of systemic chemotherapy following the completion of definitive chemoradiation. One of the challenges of this approach is being able to identify patients at highest risk for poor outcomes following chemoradiation alone. Advances in functional imaging with Positron Emission Tomography (PET) and quantification of a standardized uptake value (SUV) can provide prognostic information that may be helpful in identifying women populations at higher risk of failure, thereby allowing for an enriched patient population that is more likely to benefit from escalated therapy [5-7].

In low-middle income countries there are a limited number of cyclotrons available for PET imaging making it impossible to integrate this technology into the routine management of cervical cancer patients. MRI is, however, readily available and routinely utilized for cervical cancer staging in many countries but standard imaging sequences only provide anatomical, and not functional, information. Newer MRI sequences such as diffusion-weighted imaging (DWI) provide functional information by characterizing the diffusion of water between cells [8-10]. This can be quantitated, similar to an SUV on PET scans, by calculating an apparent diffusion coefficient (ADC) value. Previous investigators have demonstrated high concordance of tumor sub volumes with increased metabolic activity on PET with increased cellular density on DWI imaging suggesting ADC values may have similar prognostic value as $\mathrm{SUV}_{\max }[8,11]$.

DWI imaging has previously been studied in cervical cancer patients with mixed results regarding its utilization as a prognostic/predictive marker [12-14, 15-18]. Given the variation in correlations with DWI imaging, we investigated whether baseline MRI DWI imaging features correlate with clinical outcomes in women with locally advanced cervical cancer treated with definitive chemoradiation.

\section{Methods}

This was a retrospective study of cervical cancer women treated at Barretos Cancer Hospital, approved by the Research Ethics Committee. Patients were treated using radiation therapy with or without concurrent chemotherapy and who had an MRI of the pelvis performed prior to the start of treatment between January 2012 and March of 2013. A total of 135 patients were identified. Forty-six were excluded from further analysis because either their MRI was not performed at our institution or diffusion weighted imaging was not performed. Ten additional women were excluded because they were treated with palliative intent and 13 more were excluded because they did not have sufficient clinical follow-up information available. This left 66 women available for complete analysis.

The study group was classified according to the revised 2009 FIGO staging system. The extent of tumor involvement was based on both clinical examination and MRI findings (i.e. a patient with parametrial involvement on clinical examination but clear involvement on MRI imaging to the pelvic sidewall was classified as FIGO Stage IIIB). Positive lymph nodes were based on MRI findings. A lymph node was considered positive if it had a maximum diameter larger than $1 \mathrm{~cm}$ with heterogeneity of signal or an irregular contour. Enlarged lymph nodes were not routinely pathologically confirmed.

Eight patients received radiation alone and 58 were treated with chemoradiation. All 66 women received high dose rate (HDR) brachytherapy as a component of their treatment. The mean (SD) external beam and HDR doses were: 44.92 (0.62) Gy and 27.05 (1.67) Gy (7 Gy × 4 being the most common fractionation), respectively. The mean (SD) equivalent dose in 2-Gy fractions (EQD2) for external 
beam plus HDR-brachytherapy was 82.2 (2.8) Gy. There was no lymph node boost.

Radiation was delivered using a standard linear accelerator with either $6 \mathrm{MV}$ or $15 \mathrm{MV}$ beams and planned using a 3D planning method with organ at risk and target volumes contoured by a radiation oncologist. Intensity modulated radiation therapy was not used. All patients were planned using Eclipse version 8.0 (Varian Medical Systems, Palo Alto, CA, USA).

For the brachytherapy, four fractions of HDR using a tandem and ovoid applicator were delivered to all patients (except two that only received three fractions of $7 \mathrm{~Gy}$ ). The dose was prescribed to point $\mathrm{A}$ and was planned based on 2-dimmensional films. Bladder and rectal points were placed as per ICRU 38 guidelines. The constraints for a prescription of 7 Gy were $71 \%$ (bladder) and $58 \%$ (rectum). Dose prescription was diminished to $6.5 \mathrm{~Gy}$ or 6 Gy when the constraints were extrapolated. Brachytherapy planning was performed using GammaMed ${ }^{\mathrm{Tm}}$ (Varian Medical Systems Inc., Palo Alto, CA, USA).

The majority of women (82 \%) were treated with concurrent cisplatin chemotherapy at a dose of $40 \mathrm{mg} / \mathrm{m}^{2}$ weekly. Four women received concurrent carboplatin and eight did not receive concurrent chemotherapy.

All patients were followed up with physical exam, abdominal/pelvic imaging and surveillance pap smears every 3 to 6 months.

Disease recurrence was determined radiographically by RECIST 1.1 criteria [19] and was not pathologically confirmed. Local regional control was defined as the time from biopsy to local (uterine cervix or vagina) or regional recurrence (pelvic lymph node). Disease free survival (DFS) was defined as the time from biopsy to tumor progression. Disease specific survival (DSS) was defined as the time between biopsy to death by cancer.

\section{Imaging technique and analysis}

All images were performed at baseline assessment (before any treatment) on one of two scanners: Achieva 3.0 Tesla, Philips Healthcare, Netherlands or a Signa HDX'T 1.5 Tesla, GE Healthcare, Milwaukee. All patients had trans-vaginal ultrasound gel administered prior to the start of their MRI. The sequences acquired included T2weighted sequences of the whole pelvis and abdominal region below the renal arteries, axial T1-weighted sequences of the whole pelvis, T2-weighted sequences in the sagittal, axial and coronal planes at an angle through the plane of the cervix, and diffusion-weighted sequences. For the diffusion sequence, the field of view was $40 \times 40$, the matrix size was 512, with b-values of 0,600 (3 T scanner) and 0,800 (1.5 T scanner). Acquisition time was $6 \mathrm{~min}$. Voxel size was $2.34 \mathrm{~mm}$ (RL), $3.19 \mathrm{~mm}$ (AP). Repetition time was $1800 \mathrm{~ms}$ and slice thickness was $3 \mathrm{~mm}$.

After generating the ADC maps, a region of interest (ROI) was manually drawn by one of three experienced radiologists (F.R.L., A.K.B.J.N., R.R.R.) on a single DWI slice that showed the lesion at its maximum diameter, using axial FSE T2WI for guidance. PACS software (PixViewer, Viewer MPR - PIXEON) then calculated the ADC minimum $\left(\mathrm{ADC}_{\min }\right)$, mean $\left(\mathrm{ADC}_{\text {mean }}\right)$, maximum $\left(\mathrm{ADC}_{\max }\right)$ and standard deviation of the $\mathrm{ADC}$ values $\left(\mathrm{ADC}_{\mathrm{dev}}\right)(\times 10$ ${ }^{-3} \mathrm{~mm}^{2} / \mathrm{s}$ ) of the chosen region (Fig. 1).

\section{Statistical considerations}

The Mann Whitney test was used to compare ADC values of clinical-pathological and treatment-related factors including: FIGO stage (I/II vs III/IV), histology (squamous vs non-squamous), tumor grade (1-2 vs 3), lymph node status ( $\mathrm{N}+\mathrm{vs} \mathrm{N}-$ ), parametrial invasion (yes vs no), vaginal invasion (yes vs no), rectal/bladder invasion (yes vs no), Gross Tumor Volume (GTV) (greater than or less than

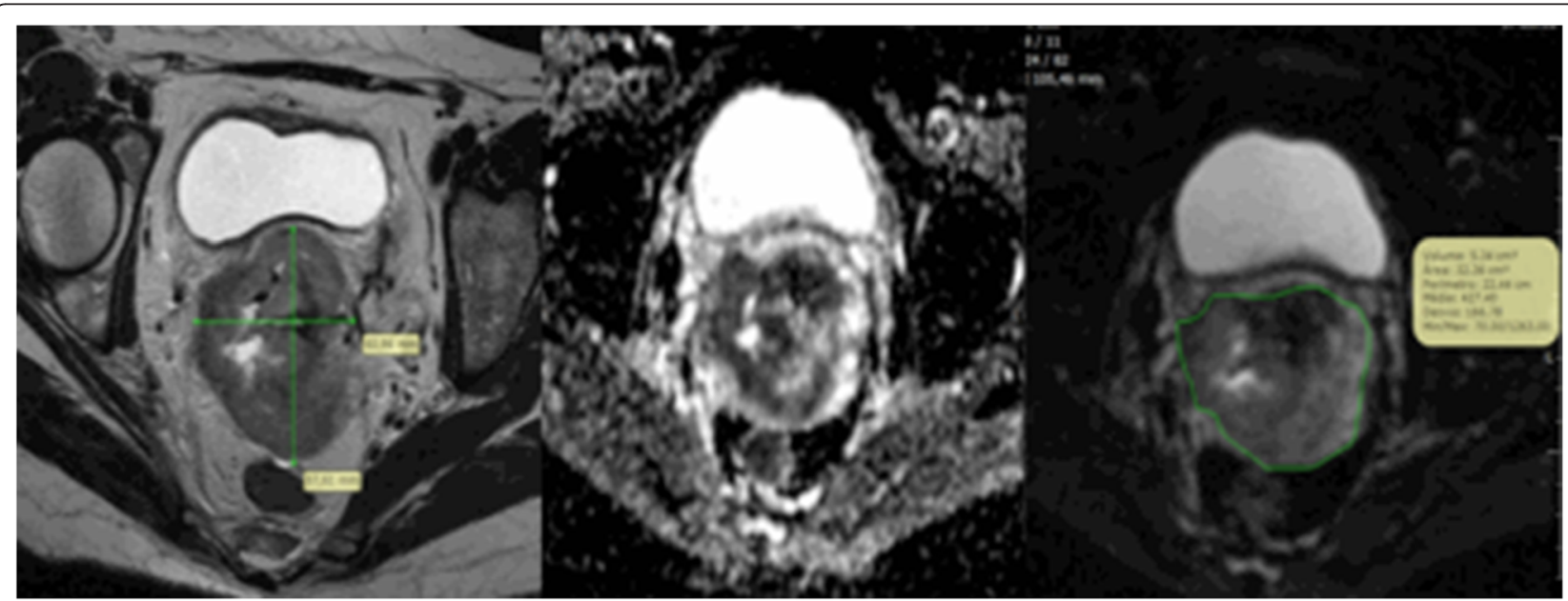

Fig. 1 Magnetic resonance imaging examples of axial slices of: T2 weighted (left), diffusion weighted imaging (center), and region of interest drawn on an attenuation diffusion coefficient map (right) 
the median), radiation dose to the primary tumor expressed as an EQD2 (greater than or less than the median) and usage of chemotherapy (yes vs no).

ROC curves were built in order to choose a cutoff value for $\mathrm{ADC}$ variables. Confirmatory multivariate Cox model analysis was used to test ADC values and associations with DFS and DSS. These models were adjusted by FIGO stage. LRC was evaluated by confirmatory logistic regression using the GTV as the adjustable variable. Three-year survival rates (DFS and DSS) were estimated according to Kaplan Meyer method. Significance level was set at $5 \%$ for all statistics.

\section{Availability of data}

The data that support our findings will not be shared due to patient privacy issues and the lack of written consent form signed by patients (retrospective study).

\section{Results}

\section{Correlations between imaging parameters and baseline} clinical features

Of the 66 women included in the analysis, 44 had FIGO stage I-II disease while 22 had stage III-IV disease. Seventy-one percent had well or moderately differentiated disease and $82 \%$ had squamous cell cancer. Additional patient details are presented in Table 1.

Table 1 Patient and treatment characteristics

\begin{tabular}{|c|c|}
\hline & $n(\%)$ \\
\hline Number of patients & 66 \\
\hline Median age at diagnosis (range) & $51.8(23.3-90.1)$ \\
\hline \multirow[t]{3}{*}{ Histology } & $\begin{array}{l}\text { Squamous: } 54 \\
(82 \%)\end{array}$ \\
\hline & $\begin{array}{l}\text { Adenocarcinoma: } \\
7(11 \%)\end{array}$ \\
\hline & $\begin{array}{l}\text { Adenosquamous: } \\
5(8 \%)\end{array}$ \\
\hline \multirow[t]{3}{*}{ Grade (differentiation) } & Well: 4 (6 \%) \\
\hline & $\begin{array}{l}\text { Moderate: } 43 \\
(65 \%)\end{array}$ \\
\hline & Poor: 19 (29\%) \\
\hline \multirow[t]{4}{*}{ FIGO Stage (2009) } & IB1-2: 2 (3 \%) \\
\hline & IIA1-IIB: 42 (64\%) \\
\hline & |IIA-B: 16 (24 \%) \\
\hline & IVA-B: 6 (9 \%) \\
\hline $\begin{array}{l}\text { Median External beam radiotherapy } \\
\text { dose (range) }\end{array}$ & $\begin{array}{l}44.92 \mathrm{~Gy} \\
(39.6-59.4)\end{array}$ \\
\hline $\begin{array}{l}\text { Median HDR Brachytherapy } \\
\text { dose (range) }\end{array}$ & 27.05 Gy $(21-28)$ \\
\hline $\begin{array}{l}\text { Median Total external beam and } \\
\text { brachytherapy dose as an EQD2 (range) }\end{array}$ & 82.2 Gy (74-83.9) \\
\hline Concurrent chemotherapy & $58(88 \%)$ \\
\hline
\end{tabular}

Table 2 shows comparisons between baseline clinical features and different ADC values. Women with FIGO stage III-IV disease had significantly higher mean $\mathrm{ADC}_{\max }$ values compared with stage I-II (1.8 vs. $1.5, p=0.007)$. Patients with imaging defined positive nodes also had significantly higher mean $\mathrm{ADC}_{\max }$ values compared with lymph node negative ones ( 2.0 vs. $1.6, p=0.029)$. No other significant correlations were seen.

\section{Treatment outcomes}

After a median follow up of 32 months (range 5-43), 11 patients $(17 \%)$ developed recurrent disease (from whom three were still alive by the time of the analysis) with a median time to recurrence of 9 months (range 5-39). Two patients developed pelvic recurrence only (one an in-field recurrence in the cervix and one in a left external iliac lymph node), five developed distant metastasis only, and four developed both pelvic/distant disease recurrence. For these four patients, the pelvic component of failure included: two in the cervix only and two in the

Table 2 Mean ADC values according to tumor stage, lymph node involvement, and MRI assessed disease extent

\begin{tabular}{|c|c|c|c|c|}
\hline & $A D C_{\text {min }}$ & $A D C_{\text {mean }}$ & $A D C_{\max }$ & $\overline{A D C_{\text {deviation }}}$ \\
\hline FIGO Stage & $(p=0.077)$ & $(p=0.227)$ & $(p=0.007)$ & $(p=0.070)$ \\
\hline $\begin{array}{l}\text { I-II ( } n=44 \\
\text { being } 22 \text { with } \\
\text { positive nodes) }\end{array}$ & 0.375 & 0.855 & 1.485 & 0.224 \\
\hline $\begin{array}{l}\text { III-IV ( } n=22, \\
\text { being } 18 \text { with } \\
\text { positive nodes) }\end{array}$ & 0.267 & 0.901 & 1.806 & 0.256 \\
\hline Lymph node & $(p=0.902)$ & $(p=0.092)$ & $(p=0.029)$ & $(p=0.154)$ \\
\hline $\begin{array}{l}\text { Positive } \\
(n=40)\end{array}$ & 0.323 & 0.959 & 1.995 & 0.232 \\
\hline $\begin{array}{l}\text { Negative } \\
(n=26)\end{array}$ & 0.341 & 0.861 & 1.551 & 0.197 \\
\hline Parametrial Invasion & $(p=0.680)$ & $(p=0.810)$ & $(p=0.081)$ & $(p=0.492)$ \\
\hline Present $(n=59)$ & 0.332 & 0.867 & 1.618 & 0.223 \\
\hline Absent $(n=7)$ & 0.404 & 0.898 & 1.371 & 0.177 \\
\hline Vaginal Invasion & $(p=0.190)$ & $(p=0.252)$ & $(p=0.203)$ & $(p=0.887)$ \\
\hline Present $(n=47)$ & 0.311 & 0.848 & 1.624 & 0.198 \\
\hline Absent $(n=19)$ & 0.410 & 0.925 & 1.513 & 0.267 \\
\hline $\begin{array}{l}\text { Adjacent structure } \\
\text { invasion (rectum } \\
\text { or bladder) }\end{array}$ & $(p=0.683)$ & $(p=0.184)$ & $(p=0.301)$ & $(p=0.829)$ \\
\hline Present $(n=21)$ & 0.353 & 0.904 & 1.702 & 0.192 \\
\hline Absent $(n=45)$ & 0.339 & 0.854 & 1.542 & 0.231 \\
\hline $\begin{array}{l}\text { Gross tumor } \\
\text { volume }(c c)^{a}\end{array}$ & $(p=0.172)$ & $(p=0.886)$ & $(p=0.147)$ & $(p=0.468)$ \\
\hline$>114.48$ & 0.295 & 0.862 & 1.674 & 0.237 \\
\hline$<114.48$ & 0.383 & 0.877 & 1.508 & 0.206 \\
\hline
\end{tabular}

${ }^{a}$ Calculated by multiplication of the tumor measures (left-right, anterior-posterior, cranial-caudal) 
cervix and pelvic lymph nodes. Six out of eight women did not receive concurrent chemo (and were free of disease by the time of the analysis.

There have been a total of nine deaths in the 66 women with a median time to death of 13 months (range 9-32). Eight patients (12\% of the total 66) have died from cervical cancer (they presented cancer recurrence) and one patient died from a pulmonary embolus who had no evidence of disease at the time of death. Baseline clinical features of the eight patients who died from cervical cancer include: median age 57 (range 36-74), 6/8 SCC, 8/8 moderate/poorly differentiated, 6/8 FIGO stage III-IV, 6/8 received chemotherapy, median GTV volume $154 \mathrm{cc}$, and median EQD2 of external beam and brachytherapy was 82 Gy (range 74-83.9).

The 3-year LRC and DFS for the entire group were 89.3 and $84.8 \%$, respectively. The 3-year DSS was $87.5 \%$. Table 3 shows the univariate analysis for correlation between clinical characteristics with DFS and DSS.

Cutoff points for predicting the analyzed outcomes were chosen by $\mathrm{ROC}$ curve analysis for $\mathrm{ADC}_{\text {min }}(0.488 \times$ $\left.10^{-3} \mathrm{~mm}^{2} / \mathrm{s}, \mathrm{AUC}=0.57 ; 95 \% \mathrm{CI}: 0.33-0.79\right), \mathrm{ADC}_{\text {mean }}$ $\left(0.827 \times 10^{-3} \mathrm{~mm}^{2} / \mathrm{s}, \mathrm{AUC}=0.72 ; 95 \%\right.$ CI: $\left.0.56-0.88\right)$,

Table 3 Univariate analysis for disease specific survival and disease free survival

\begin{tabular}{|c|c|c|c|c|c|c|}
\hline \multirow[b]{2}{*}{ Variable } & \multirow[b]{2}{*}{ Category } & \multirow[b]{2}{*}{$n$} & \multicolumn{2}{|c|}{$\begin{array}{l}\text { Disease specific } \\
\text { survival }\end{array}$} & \multicolumn{2}{|c|}{$\begin{array}{l}\text { Disease free } \\
\text { survival }\end{array}$} \\
\hline & & & $\begin{array}{l}3-y \\
\text { DSS }\end{array}$ & $p$-value & $\begin{array}{l}3-y \\
\text { DFS }\end{array}$ & $p$-value \\
\hline \multirow[t]{2}{*}{ FIGO } & $1 / \|$ & 44 & 95.3 & 0.007 & 90.9 & 0.018 \\
\hline & III / IV & 22 & 72 & & 72.7 & \\
\hline \multirow[t]{2}{*}{ Lymph node } & Positive & 40 & 79.1 & 0.015 & 74.9 & 0.024 \\
\hline & Negative & 26 & 100 & & 100 & \\
\hline \multirow[t]{2}{*}{ Parametrial Invasion } & Present & 59 & 85.9 & 0.304 & 83 & 0.816 \\
\hline & Absent & 7 & 100 & & 100 & \\
\hline \multirow[t]{2}{*}{ Vaginal Invasion } & Present & 47 & 84.3 & 0.265 & 82.9 & 0.850 \\
\hline & Absent & 19 & 94.7 & & 89.5 & \\
\hline \multirow{2}{*}{$\begin{array}{l}\text { Adjacent Structures } \\
\text { Invasion }\end{array}$} & Present & 21 & 71.1 & 0.005 & 69.3 & 0.015 \\
\hline & Absent & 45 & 95.3 & & 93 & \\
\hline \multirow[t]{2}{*}{ GTV $\left(^{(a)}\right.$} & $<114.48$ & 41 & 97.6 & 0.001 & 95.1 & 0.003 \\
\hline & $>114.48$ & 25 & 69.4 & & 68 & \\
\hline \multirow[t]{2}{*}{$A D C_{\min }\left({ }^{a}\right)$} & $<0.488$ & 45 & 93.1 & 0.060 & 90.9 & 0.073 \\
\hline & $>0.488$ & 21 & 76.2 & & 72.7 & \\
\hline \multirow[t]{2}{*}{$A D C_{\text {mean }}\left({ }^{\mathrm{a}}\right)$} & $<0.827$ & 25 & 100 & 0.017 & 96 & 0.037 \\
\hline & $>0.827$ & 41 & 79.3 & & 77.9 & \\
\hline \multirow[t]{2}{*}{$A D C_{\max }\left({ }^{a}\right)$} & $<1.838$ & 51 & 93.9 & 0.002 & 90.2 & 0.053 \\
\hline & $>1.838$ & 15 & 64.6 & & 66 & \\
\hline \multirow[t]{2}{*}{$A D C_{\text {dev }}\left({ }^{a}\right)$} & $<0.148$ & 16 & 100 & 0.088 & 93.8 & 0.221 \\
\hline & $>0.148$ & 50 & 83.2 & & 81.9 & \\
\hline
\end{tabular}

( ${ }^{a}$ C) toff values were defined by ROC curve analysis
$\mathrm{ADC}_{\max }\left(1.838 \times 10^{-3} \mathrm{~mm}^{2} / \mathrm{s}, \mathrm{AUC}=0.70 ; 95 \% \mathrm{CI}: 0.50-\right.$ $0.90)$ and $\mathrm{ADC}_{\mathrm{dev}}\left(0.148 \times 10^{-3} \mathrm{~mm}^{2} / \mathrm{s}, \mathrm{AUC}=0.60 ; 95 \%\right.$ CI: 0.41-0.78).

Tables 4 and 5 show the multivariate analysis for LRC and survival, respectively. No ADC value was correlated with $\mathrm{LRC} . \mathrm{ADC}_{\text {min }}$ higher than the cut off was independently associated with worse DFS (HR $=3.6-95 \%$ CI: 1.09 $12.05 ; p=0.035)$ and DSS (HR $=4.4-95 \%$ CI: $1.05-18.5$; $p=0.043)$. Figures 2 and 3 show Kaplan Meyer curves for DFS and DSS, respectively.

\section{Discussion}

Recent advances in imaging have improved the ability to characterize the full extent of local disease extension, pelvic/para aortic lymph node involvement, and the presence of distant metastasis in cervical cancer patients [11]. Functional information derived from PET/CT like the $\mathrm{SUV}_{\max }$ can also be prognostic [5-7]. Unfortunately this advance in PET/CT imaging is not readily available in developing countries such as Brazil. MRI imaging is, however, more accessible. MRI has the advantage of providing superior soft tissue anatomy compared with CT, which in turn improves assessment of locoregional disease. In addition, functional MRI sequences have the potential to make MRI more than just an anatomic tool. Areas of interest can be contoured on DWI imagined and be quantified by calculating an ADC value. DWI imaging is also very practical in that it does not require much additional scan time or require intravenous contrast [10, 12-14].

In this study we found that pre-treatment $\mathrm{ADC}_{\max }$ was significantly correlated with FIGO stage and radiographically enlarged lymph nodes. A recent study from Memorial Sloan Kettering Cancer Center also showed a significant

Table 4 Multivariate logistic regression models for local regional control

\begin{tabular}{lllll}
\hline Variables & Category $\left({ }^{*} 1\right)$ & $n$ & $\mathrm{HR}\left({ }^{*} 2\right)$ & $95 \% \mathrm{Cl}$ \\
\hline $\mathrm{ADC}_{\text {min }}$ & $<0.488$ & 45 & Ref. & \\
& $>0.488$ & 21 & 3.9 & $\begin{array}{l}0.6-27.7 \\
(p=0.169)\end{array}$ \\
& & & & \\
$\mathrm{ADC}_{\text {mean }}$ & $<0.827$ & 25 & Ref. & \\
& $>0.827$ & 41 & 1.7 & $0.2-17.7$ \\
& & & & $(p=0.650)$ \\
ADC $_{\max }$ & $<1.838$ & 51 & Ref. & \\
& $>1.838$ & 15 & 1.3 & $0.2-10.0$ \\
ADC $_{\text {dev }}$ & $<0.148$ & 16 & Ref. & $(p=0.771)$ \\
& $>0.148$ & 50 & 0.9 & $0.1-9.7$ \\
& & & & $(p=0.934)$
\end{tabular}

$H R$ hazard ratio, $\mathrm{Cl}$ confidence interval, Ref reference

$\left.{ }^{*} 1\right)$ Cutoff values were defined by ROC curve analysis

(*2) Each model was adjusted by Gross Tumor Volume (GTV: cutoff value $=114.48$ ) 
Table 5 Multivariate models for disease specific survival and disease free survival

\begin{tabular}{|c|c|c|c|c|c|c|}
\hline \multirow[b]{2}{*}{ Variable } & \multirow[b]{2}{*}{ Category $\left({ }^{*} 1\right)$} & \multirow[b]{2}{*}{$N$} & \multicolumn{2}{|c|}{$\begin{array}{l}\text { Disease specific } \\
\text { survival }\end{array}$} & \multicolumn{2}{|c|}{$\begin{array}{l}\text { Disease free } \\
\text { survival }\end{array}$} \\
\hline & & & $\mathrm{HR}\left({ }^{*} 2\right)$ & $95 \% \mathrm{Cl}$ & $H R$ & $95 \% \mathrm{Cl}$ \\
\hline & $<0.488$ & 45 & Ref & & Ref & \\
\hline \multirow[t]{2}{*}{$A D C_{\min }$} & $>0.488$ & 21 & 4.4 & $\begin{array}{l}1.1-18.5 \\
(p=0.043)\end{array}$ & 3.6 & $\begin{array}{l}1.1-12.1 \\
(p=0.035)\end{array}$ \\
\hline & $<0.827$ & 25 & Ref & & Ref & \\
\hline \multirow[t]{2}{*}{$A D C_{\text {mean }}$} & $>0.827$ & 41 & 277.3 & $\begin{array}{l}0.0-2.7 \\
(p=0.963)\end{array}$ & 4.9 & $\begin{array}{l}0.6-39.5 \\
(p=0.138)\end{array}$ \\
\hline & $<1.838$ & 51 & Ref & & Ref & \\
\hline \multirow[t]{2}{*}{$A D C_{\max }$} & $>1.838$ & 15 & 4.3 & $\begin{array}{l}1.0-19.3 \\
(p=0.056)\end{array}$ & 2.1 & $\begin{array}{l}0.6-7.3 \\
(p=0.255)\end{array}$ \\
\hline & $<0.148$ & 16 & Ref & & Ref & \\
\hline$A D C_{\text {dev }}$ & $>0.148$ & 50 & 202.5 & $\begin{array}{l}0.0-2.4 \\
(p=0.969)\end{array}$ & 2.7 & $\begin{array}{l}0.4-21.1 \\
(p=0.354)\end{array}$ \\
\hline
\end{tabular}

HR hazard ratio, $\mathrm{Cl}$ confidence interval, Ref reference

$\left({ }^{*} 1\right)$ Cutoff values were defined by ROC curve analysis

(*2) Each model was adjusted by FIGO staging (I/II vs III/IV)

correlation between pretreatment $\mathrm{ADC}_{\text {mean }}$ with $\mathrm{FIGO}$ stage and the presence of positive lymph nodes [15]. However, while their study showed significantly higher $\mathrm{ADC}_{\text {mean }}$ for earlier staged disease and uninvolved nodes we found exactly the opposite result (higher values of $\mathrm{ADC}_{\max }$ for higher staged disease and positive nodes). This difference demonstrates some of the challenges of comparing results between studies given non-standardized methods for calculating and reporting ADC results and is discussed further below.

Investigating whether baseline $\mathrm{ADC}$ values might be a prognostic imaging biomarker may be more important than a correlation with baseline tumor characteristics. If validated this would give us an opportunity to consider risk adapting patients at the start of their treatment rather than waiting until a recurrence or subjecting all patients to an increased intensity regimen, where only a few might actually benefit. Whether ADC values are prognostic, similar to $\mathrm{SUV}_{\text {max }}$, is an area of active investigation with existing publications showing both increased and decreased pre-treatment ADC tumor values correlating with clinical outcomes [20-22].

The literature to date using ADC for assessing prognosis has predominantly focused on metrics such as $\mathrm{ADC}_{\text {min }}, \mathrm{ADC}_{\text {max }}, \mathrm{ADC}_{\text {mean }}$, and $\mathrm{ADC}$ percentiles when a histogram-based analysis is used. One recent histogram based analysis includes a recent study of 85 cervical cancer women treated with chemoradiation demonstrating a lower baseline absolute and normalized ADC $95^{\text {th }}$ percentile is associated with shorter disease free survival on multivariate analysis [16]. Other groups have reported on using $\mathrm{ADC}$ information gleaned from a single MRI slice. In one retrospective study of 45 cervical cancer women treated with a mix of definitive surgery and chemoradiation, a lower pretreatment $\mathrm{ADC}_{\text {mean }}$ was predictive of

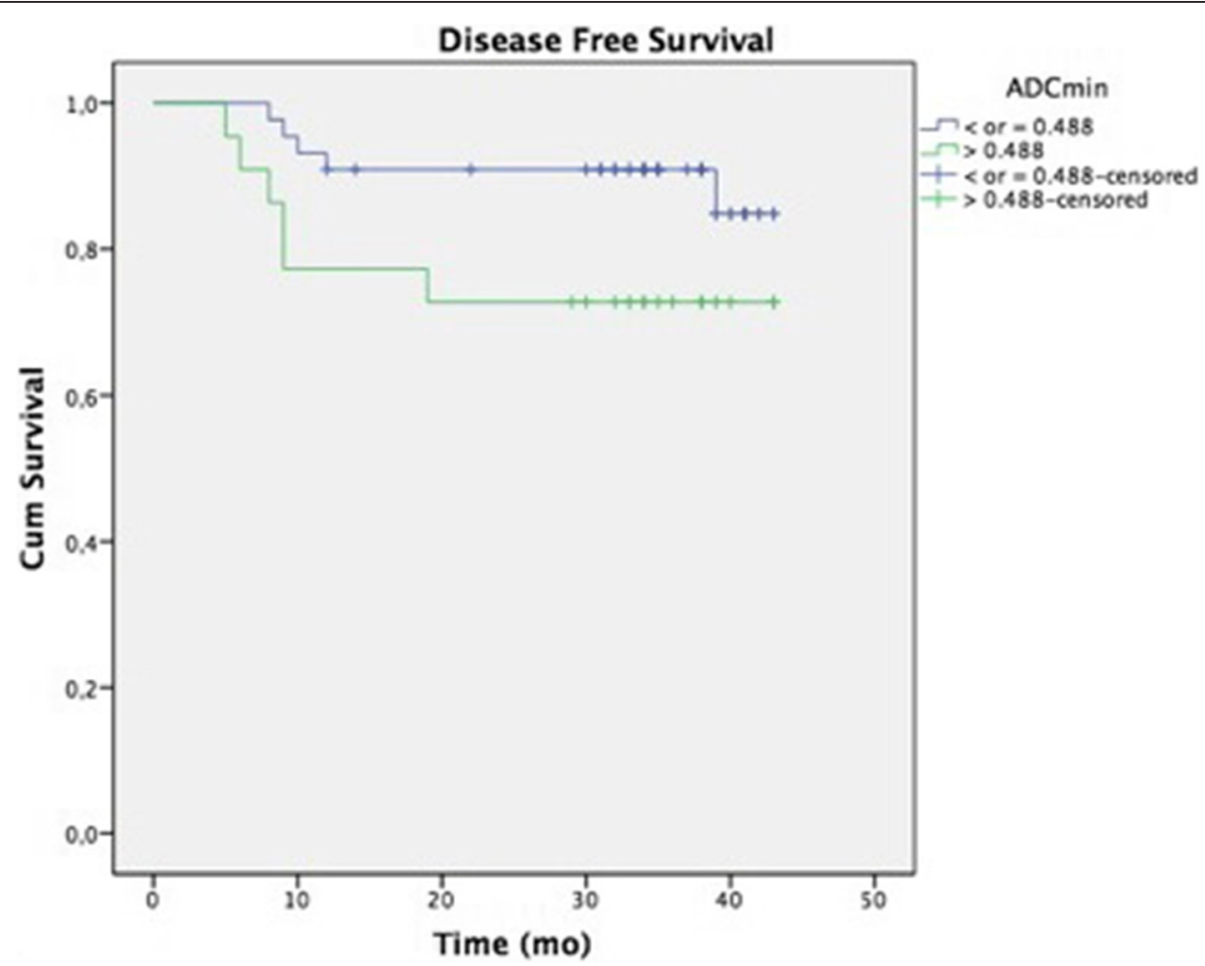

Fig. 2 Kaplan Meyer curve for DFS 


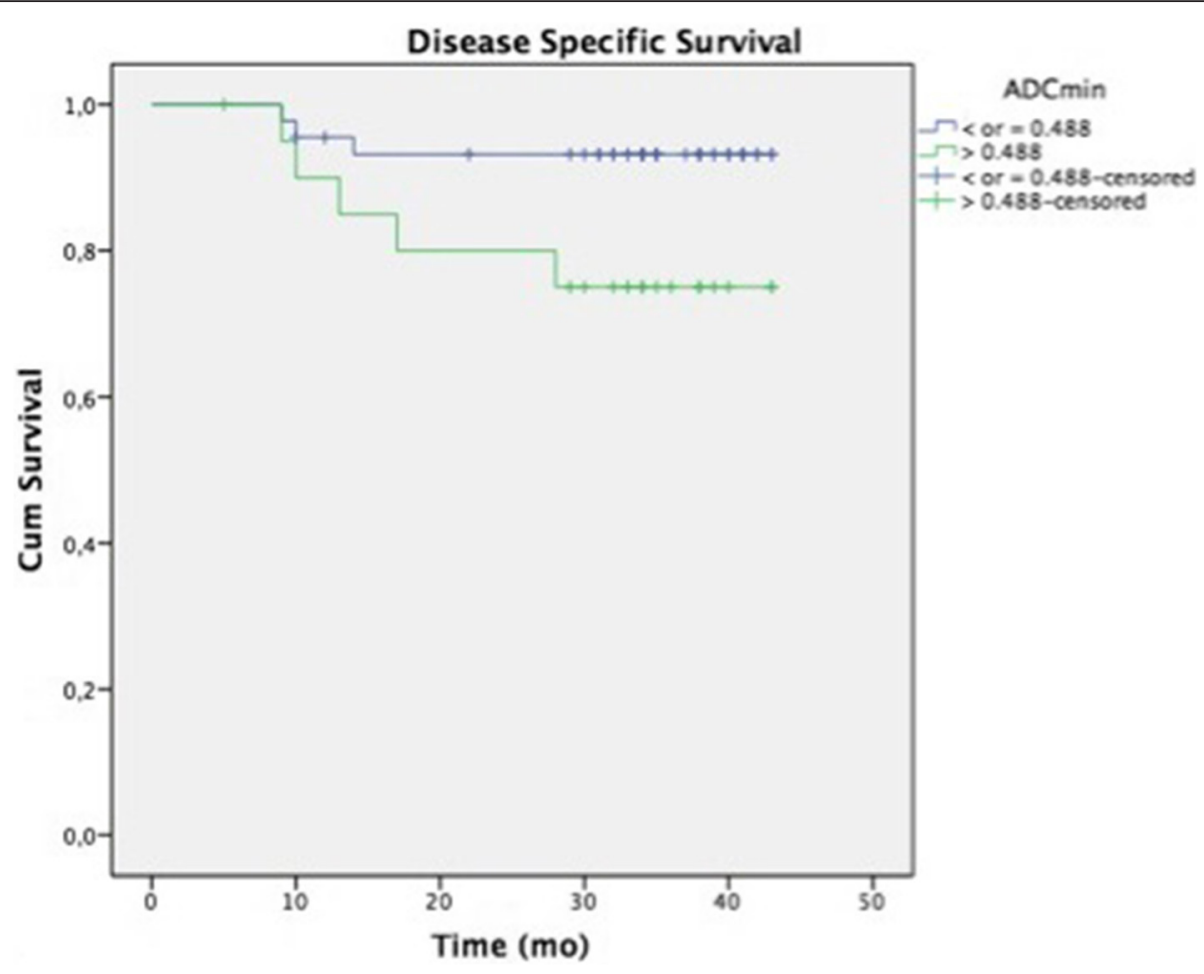

Fig. 3 Kaplan Meyer curve for DSS

both disease free and overall survival [15]. While these are two of the larger studies published to date looking at correlations between ADC values and clinical outcomes in cervical cancer, there are multiple studies that have been published on this topic with variation in the correlation between ADC values and outcomes. Some studies have correlated higher pre-treatment $\mathrm{ADC}$ values with inferior outcomes, while others have correlated lower pre-treatment values with inferior outcomes. These inconsistencies are likely related to multiple factors including: the heterogeneity of the patients, different treatments (surgery vs chemoradiation), various histologies (squamous cell cancer vs adenocarcinoma), use of a single slice region of interests for calculating ADC values which can underestimate the true heterogeneity of the overall tumor, different MRI imaging protocols, retrospective study design, different time points for assessing treatment response, and small patient numbers. These discrepancies point to some of the challenges in comparing data across various studies. Moving forward there needs to be agreed upon imaging and reporting standards so that data can be compared across different institutions. This is not a problem unique to DWI and similar discrepancies have been reported for dynamic contrast enhanced MRI studies in cervical cancer [17].

We looked at standard ADC metrics like the minimum, maximum and mean but also evaluated the $\mathrm{ADC}_{\text {dew }}$ which has not been previously reported on. $\mathrm{ADC}_{\text {min }}$ and $\mathrm{ADC}_{\text {max }}$ represent extreme values that can be very sensitive to tumor composition, i.e., extremely high or extremely low ADC sub-volumes (which could have prognostic value). The fact that $\mathrm{ADC}_{\text {mean }}$ represents a much larger amount of information (it represents the mean value of all voxels measures including the $\mathrm{ADC}_{\text {min }}$ and $\mathrm{ADC}_{\text {max }}$ ) could explain the observation that it reached significance only in the univariate analysis but didn't do in the multivariate where only $\mathrm{ADC}_{\text {min }}$ was significantly associated to outcomes - higher values were correlated with poorer DSS and DFS. A number of studies have linked ADC values to therapy outcomes, with most of them showing that tumors with higher values respond less favorably to therapy [23-27] . Mechanistically this may be explained by the presence of microscopic and macroscopic tumoral necrosis, which can increase ADC values and is linked to poorer outcomes [18, 28]. Our data is in contrast however to Nakamura et al. [29] who analyzed the combination of $\mathrm{ADC}_{\min }$ and $\mathrm{SUV}_{\max }$ in 66 women with cervical cancer. Women with lower $\mathrm{ADC}_{\text {min }}$ showed decreased OS compared to those with the highest values. The fact that we found exactly the opposite in our study (highest values of $\mathrm{ADC}_{\text {min }}$ predicting worse $\mathrm{DSS}$ ) only exemplifies the difficulties in interpreting this data without standardized reporting.

When looking at the makeup of the patients who died from cervical cancer one can see that although the majority had advanced features (FIGO III/IV disease, 
moderate/poorly differentiated SCC, and large GTV volumes) that there were many patients with similar features who had positive outcomes. This emphasizes the limitations of our current risk stratification schemes that focus on clinical and pathologic features without integrating information about the biology of the tumors. While the underlying biology responsible for variations in $A D C$ values in cervical cancer is not known it does provide functional information that is currently not incorporated into our standard risk stratification tools. Given that the dominant pattern of failure in our cohort included a component of distant failure (nine out of 11 cases) it is critical that we identify women at high risk of distant failure as early on in the natural history of their disease as possible in an effort to improve their outcomes. With additional data it's possible that information gleaned from functional imaging could help identify high risk populations either independently or synergistically with our current clinically based stratification.

There are some weaknesses of our study which include its retrospective design. This contributes to differences in the timing and method of assessment of clinical response as well as the different b-values used for the DWI studies. Variation in b-values occurred due to the adoption of different imaging protocols over time. A study published by Hoogendam et al. however reported that changing the tested b-value combinations did not influence the ADC-based differentiation of benign tissue from malignant tissue and so it is not clear if this impacted the results of this study [30]. Also, we limited the number of adjusted variables in the confirmatory multivariate model in order to avoid an over fitting due to the relative small number of events [31]. Hence, we decided to use well-known prognostic factors as adjusted variables such as FIGO stage for DSS and DFS and GTV for LRC. Moreover, patients were treated using 2-dimmentional brachytherapy and did not have their enlarged lymph nodes boosted. This might have impacted the patterns of failure and ultimate treatment outcomes as has been suggested by the improved outcomes using 3-dimmentional image guided brachytherapy data, however, the local failure rates in this series are low and the predominant failure pattern was distant which is in line with more modern image guided outcomes.

These findings need to be validated in a prospective setting and we have already open a clinical trial measuring $\mathrm{ADC}$ values at baseline, mid-treatment, and 3 months posttreatment in patients being treated with chemoradiation for cervical cancer. Ultimately a prospective trial will help determine whether baseline or mid-treatment MRI features, as has been suggested by others are independent predictors of outcomes and whether this could be used for selecting patients that may benefit from escalated treatment $[32,33]$.

\section{Conclusions}

Pre-treatment $\mathrm{ADC}_{\max }$ measured in the primary tumor may be associated with FIGO stage and lymph node status. Higher pre-treatment $\mathrm{ADC}_{\min }$ measured in the primary tumor of cervical cancer might predict worse disease free survival and disease specific survival in patients treated with definitive chemoradiation. Prospective validation of these findings is currently ongoing.

\section{Abbreviations}

$A D C$, apparent diffusion coefficient; $A D C$ dev, standard deviation of the $A D C$; $A D C$ max, maximum value of $A D C ; A D C$ mean, mean value of $A D C ; A D C$ min, minimum value of ADC; AUC, area under curve; $\mathrm{Cl}$, confidence interval; DFS, disease free survival; DSS, disease specific survival; DW, diffusion weighted; $H D R$, high dose rate; HR, hazard ratio; LRC, local regional control; MRI, magnetic resonance imaging; PET, positron emission tomography; ROC, receiver operating characteristic; $\mathrm{ROI}$, region of interest; SCC, squamous cell carcinoma; SD, standard deviation; SUV, standardized uptake value

\section{Acknowledgements}

We'd like to thanks Dr. Marcelo Dimas Spadim, Dr Fernanda Buongusto, Dr Tatiana Leitão Azevedo, Ligia Zampiere de Britto, Talita Gracia do Nascimento and Mr. Roy Hary (BS, EMT, USA) by the support with this paper.

Availability of data and materials

The datasets generated during and/or analysed during the current study are not publicly available due to confidentially reasons but are available from the corresponding author on reasonable request.

\section{Authors' contributions}

DGM discussed the initial purpose of the study (conception, design), collected clinical data and drafted the manuscript. JHTGF discussed the initial purpose of the study (conception, design), performed the statistical analysis and drafted the paper. RRR discussed the initial purpose of the study (conception, design), collected radiological data and drafted the manuscript. AKBJN discussed the initial purpose of the study (conception, design), collected radiological data and drafted the manuscript. FRL discussed the initial purpose of the study (conception, design), collected radiological data and drafted the manuscript. ATT discussed the initial purpose of the study (conception, design) and drafted the manuscript. MK discussed the initial purpose of the study and drafted the manuscript. All authors read and approved the final manuscript.

\section{Competing interests}

The authors declare that they have no competing interests.

Consent for publication

Not applicable.

\section{Ethics approval and consent to participate}

As a retrospective study, consent inform was not given to patients. However, patient records/information was anonymized and de-identified prior to analysis. It was approved by the Barretos Cancer Hospital Institutional Review Board.

Research involving animals

Not applicable.

Research involving plants

Not applicable.

Trial registration

Not applicable.

\section{Author details}

'Department of Radiation Oncology, Barretos Cancer Hospital, Antenor Duarte Villela, 1331, Barretos, Sao Paulo 14784-400, Brazil. ²Department of Gynecology Oncology, Barretos Cancer Hospital, Barretos, Sao Paulo, Brazil. ${ }^{3}$ Department of Radiology, Barretos Cancer Hospital, Barretos, Sao Paulo, 
Brazil. ${ }^{4}$ Department of Radiation Oncology, University of California Los Angeles, Los Angeles, CA, USA

\section{Received: 15 April 2016 Accepted: 26 July 2016} Published online: 28 July 2016

\section{References}

1. Torre LA, Bray F, Siegel RL, Ferlay J, Lortet-Tieulent J, Jemal A. Global cancer statistics, 2012. CA Cancer J Clin. 2015;65(2):87-108.

2. Schmid MP, Franckena M, Kirchheiner K, Sturdza A, Georg P, Dörr W, et al. Distant metastasis in patients with cervical cancer after primary radiotherapy with or without chemotherapy and image guided adaptive brachytherapy. Gynecol Oncol. 2014;133(2):256-62.

3. Tewari KS, Sill MW, Long 3rd HJ, Penson RT, Huang H, Ramondetta LM, et al. Improved survival with bevacizumab in advanced cervical cancer. N Engl J Med. 2014;370(8):734-43

4. https://www.rtog.org/LinkClick.aspx?fileticket=|U6JlzhBt7s\%3D\&tabid=290 (2016). Accessed 25 Mar 2016.

5. Kidd EA, Siegel BA, Dehdashti F, Grigsby PW. Pelvic lymph node F-18 fluorodeoxyglucose uptake as a prognostic biomarker in newly diagnosed patients with locally advanced cervical cancer. Cancer. 2010;116(6):1469-75.

6. Kidd EA, Siegel BA, Dehdashti F, Grigsby PW. The standardized uptake value for F-18 fluorodeoxyglucose is a sensitive predictive biomarker for cervical cancer treatment response and survival. Cancer. 2007;110(8):1738-44.

7. Siva S, Deb S, Young RJ, Hicks RJ, Callahan J, Bressel M, Mileshkin L, et al. F-FDG PET/CT following chemoradiation of uterine cervix cancer provides powerful prognostic stratification independent of HPV status: a prospective cohort of 105 women with mature survival data. Eur J Nucl Med Mol Imaging. 2015;42(12):1825-32.

8. Olsen JR, Esthappan J, DeWees T, Narra VR, Dehdashti F, Siegel BA, et al. Tumor volume and subvolume concordance between FDG-PET/CT and diffusion-weighted MRI for squamous cell carcinoma of the cervix. J Magn Reson Imaging. 2013;37(2):431-4.

9. Matsushima N, Maeda M, Takamura M, Takeda K. Apparent diffusion coefficients of benign and malignant salivary gland tumors. Comparison to histopathological findings. J Neuroradiol. 2007;34:183-9.

10. Abdel Razek AA, Soliman NY, Elkhamary S, Alsharaway MK, Tawfik A. Role of diffusion-weighted MR imaging in cervical lymphadenopathy. Eur Radiol. 2006:16:1468-77.

11. Sun H, Xin J, Zhang S, Guo Q, Lu Y, Zhai W, et al. Anatomical and functional volume concordance between FDG PET, and T2 and diffusion-weighted MRI for cervical cancer: a hybrid PET/MR study. Eur J Nucl Med Mol Imaging. 2014:41(5):898-905.

12. McVeigh PZ, Syed AM, Milosevic M, Fyles A, Haider MA. Diffusion-weighted MRI in cervical cancer. Eur Radiol. 2008;18:1058-64.

13. Rizzo S, Summers P, Raimondi S, Belmonte M, Maniglio M, Landoni F, et al. Diffusion-weighted MR imaging in assessing cervical tumour response to nonsurgical therapy. Radiol Med. 2011;116:766-80.

14. Liu Y, Bai R, Sun H, Liu H, Wang D. Diffusion-weighted magnetic resonance imaging of uterine cervical cancer. J Comput Assist Tomogr. 2009;33:858-62.

15. Miccò M, Vargas HA, Burger IA, Kollmeier MA, Goldman DA, Park KJ. Combined pre-treatment MRI and 18-FDG PET/CT parameters as prognostic biomarkers in patients with cervical cancer. Eur J Radiol. 2014;83:1169-76.

16. Gladwish A, Milosevic M, Fyles A, Xie J, Halankar J, Metser U. Association of appartent diffusion coefficient with disease recurrence in patients with locally advanced cervical cancer treated with radical chemotherapy and radiation therapy. Radiology. 2016;279(1):158-66.

17. Lund KV, Simonsen TG, Hompland T, Kristensen GB, Rofstad EK. Short-term pretreatment DCE-MRI in prediction of outcome in locally advanced cervical cancer. Radiother Oncol. 2015;115(3):379-85

18. Padhani AR, Liu G, Mu-Koh D, Chenevert TL, Toeny HC, Takahara T, et al. Diffusion-weighted magnetic resonance imaging as a cancer biomarker: consensus and recommendations. Neoplasia. 2009;11:102-25.

19. Eisenhauer EA, Therasse $P$, Bogaerts J, Schwartz LH, Sargent D, Ford R, et al. New response evaluation criteria in solid tumours: Revised RECIST guideline (version 1.1). Eur J Cancer. 2009;45(2):228-47.

20. Naganawa S, Sato C, Kumada H, Ishigaki T, Miura S, Takizawa O. Apparent diffusion coefficient in cervical cancer of the uterus: comparison with the normal uterine cervix. Eur Radiol. 2005;15:71-8.
21. Frederick L, Greene David L, Page Irvin D, Fleming April G, Fritz Charles M, Balch Daniel G, et al. AJCC cancer staging manual. 6th ed. New York: Springer; 2002.

22. Wright JD, Dehdashti F, Herzog TJ, Mutch DG, Huettner PC, Rader JS, et al. Preoperative lymph node staging of early-stage cervical carcinoma by [18F]-fluoro-2-deoxy-D-glucose-positron emission tomography. Cancer. 2005;104:2484-91.

23. Koh DM, Padhani AR. Diffusion-weighted MRI: a new functional clinical technique for tumour imaging. Br J Radiol. 2006;79:633-5.

24. Lemaire L, Howe FA, Rodrigues LM, Griffiths JR. Assessment of induced rat mammary tumour response to chemotherapy using the apparent diffusion coefficient of tissue water as determined by diffusion-weighted $1 \mathrm{H}-\mathrm{NMR}$ spectroscopy in vivo. Magma. 1999;8:20-6.

25. Dzik-Jurasz A, Domenig C, George M, Wolber J, Padhani A, Brown G, et al. Diffusion MRI for prediction of response of rectal cancer to chemoradiation. Lancet. 2002;360:307-8.

26. DeVries AF, Kremser C, Hein PA, Griebel J, Krezcy A, Ofner D, et al. Tumor microcirculation and diffusion predict therapy outcome for primary rectal carcinoma. Int J Radiat Oncol Biol Phys. 2003;56:958-65.

27. Cui Y, Zhang XP, Sun YS, Tang L, Shen L. Apparent diffusion coefficient: potential imaging biomarker for prediction and early detection of response to chemotherapy in hepatic metastases. Radiology. 2008;248:894-900.

28. Li SP, Padhani AR. Tumor response assessments with diffusion and perfusion. J Magn Reson Imaging. 2012;35(4):745-63.

29. Nakamura K, Joja I, Kodama J, Hongo A, Hiramatsu Y. Measurement of SUVmax plus ADCmin of the primary tumor is a predictor of prognosis in patients with cervical cancer. Eur J Nucl Med Mol Imaging. 2012;39:283-90.

30. Hoogendam JP, Klerkx WM, de Kort GA, Bipat S, Zweemer RP, Sie-Go DM, et al. The influence of the b-value combination on apparent diffusion coefficient based differentiation between malignant and benign tissue in cervical cancer. J Magn Reson Imaging. 2010;32:376-82.

31. Vittinghoff $E$, McCulloch CE. Relaxing the rule of ten events per variable in logistic and Cox regression. Am J Epidemiol. 2007;165(6):710-8.

32. Park JJ, Kim CK, Park SY, Simonetti AW, Kim E, Park BK, et al. Assessment of early response to concurrent chemoradiotherapy in cervical cancer: value of diffusion-weighted and dynamic contrast-enhanced MR imaging. Magn Reson Imaging. 2014;32:993-1000.

33. Nakamura K, Joja I, Nagasaka T, Fukushima C, Kusumoto T, Seki N, et al. The mean apparent diffusion coefficient value (ADCmean) on primary cervical cancer is a predictive marker for disease recurrence. Gynecol Oncol. 2012; 127:478-83.

\section{Submit your next manuscript to BioMed Central and we will help you at every step:}

- We accept pre-submission inquiries

- Our selector tool helps you to find the most relevant journal

- We provide round the clock customer support

- Convenient online submission

- Thorough peer review

- Inclusion in PubMed and all major indexing services

- Maximum visibility for your research

Submit your manuscript at www.biomedcentral.com/submit
) Biomed Central 